University of Warwick institutional repository: http://go.warwick.ac.uk/wrap

This paper is made available online in accordance with publisher policies. Please scroll down to view the document itself. Please refer to the repository record for this item and our policy information available from the repository home page for further information.

To see the final version of this paper please visit the publisher's website. Access to the published version may require a subscription.

Author(s): Hazra, Sumit, Williams, David, Roy, Rajat, Aylmore, R. and Smith, A.

Article Title: Effect of material and process variability on the formability of aluminium alloys

Year of publication: 2011

Link to published article:

http://dx.doi.org/10.1016/j.jmatprotec.2011.04.001

Publisher statement: NOTICE: this is the author's version of a work that was accepted for publication in Journal of Materials Processing Technology. Changes resulting from the publishing process, peerreview, editing, corrections, structural formatting, and other quality control mechanisms may not be reflected in this document. Changes may have been made to this work since it was submitted for publication. A definitive version was subsequently published in Journal of Materials Processing Technology. (2011). 211(9), pp. 1516-1526. 10.1016/j.jmatprotec.2011.04.001. 


\title{
Effect of Material and Process Variability on the Formability of Aluminium Alloys
}

\author{
S. Hazra ${ }^{\mathrm{a}, *}$, D. Williams ${ }^{\mathrm{a}}$, R. Roy ${ }^{\mathrm{a}}$, R. Aylmore ${ }^{\mathrm{b}}$ and A. Smith ${ }^{\mathrm{C}}$ \\ ${ }^{\mathrm{a}}$ Warwick Manufacturing Group, University of Warwick, Gibbett Hill Road, Coventry CV8 2PS UK \\ b Land Rover, Banbury Rd, Gaydon, Warwick, CV35 0RR, UK \\ C Jaguar Cars Limited, Abbey Road, Whitley, Coventry, CV3 4LF, UK
}

${ }^{*}$ Corresponding author.

E-mail address: sumit.hazra@warwick.ac.uk

Telephone: +44(0)2476575409

Fax: +44(0)2476575403 


\begin{abstract}
Automotive parts are increasingly being manufactured to be lighter and stronger to minimise the environmental impact and to improve the crash performance of automobiles. The materials that are being used to achieve these aims tend to have lower formabilities compared to the traditionally used mild steel. This is particularly true for cold forming operations. As a consequence of the smaller forming window that is available, there is a greater need to understand the safety margins that are applied when manufacturing parts made from these materials. These safety margins are determined by estimations of the impact of material and process variabilities on formability as well as the attitude that is adopted towards risk. This study looked at the impact of material and process variabilities on the cold formability of two aluminium grades: AA6111-T4 and AA5754-O. The forming factors studied included changes to overall material properties, tool surface roughness, quantity of lubricant, tooling temperature and gauge. Because of the complexity of the forming process, the problem was reduced to a study of formability under plane strain stretch conditions. Particular emphasis was placed in quantifying the temperature of tooling during cold forming and understanding its effect on formability. It was found that the safety factor applied to AA5754-O can be lower than that used for AA6111-T4.
\end{abstract}




\section{Introduction}

Sheet metal forming is a cold forming process where material deformation and tool-material interactions take place under changing conditions that may arise, for example, through increasing tooling temperature. Although the process is complex, formability of parts may be predicted using finite element models that account for tool geometry, blank material properties and friction conditions. The parameters used to describe these models are usually specified deterministically so that a perfectly repeatable process is assumed. In reality, the parameters of the stamping process vary. For example, Blumel et al. (1988) measured the mechanical properties of every $400^{\text {th }}$ blank during serial production and showed that the variability in properties, which was quantified in terms of standard deviation, depended on the grade of steel used. To ensure a robust process, such variability is accounted for within safety margins that may be applied to the forming limit curve. Components, however, are increasingly being manufactured using higher strength and lighter materials that are relatively less formable. At the same time, cost pressures mean that parts have increasingly complex geometries to serve multiple purposes to reduce part count. In this context, parts that are overly 'safe' can limit these competing requirements. Consequently, there is a need to better understand the impact of variability in the stamping process so that an appropriate level of safety margins may be used in the design of parts.

This investigation looked into the effect of the variability of material and process parameters on formability, particularly that of tooling temperature. The materials studied were two aluminium grades, AA5754-O and AA6111-T4, which are used in automotive applications. The objective of this study was to understand the sensitivity of the two grades with respect to changes to parameters that influence their formability and to infer the relative safety margins that may be used in the design of parts using these materials. The magnitude of the parameter values were chosen to reflect the levels seen in an industrial environment. Of 
the material and process parameters that were identified as having the most influence on the formability of AA6111-T4 and AA5754-O, tooling temperature during the cold forming process has been studied the least. An initial investigation was therefore carried out to determine the extent of the temperature rise that occurs in typical aluminium parts during serial production. The effect of the variability of the identified parameters was then tested in

plane strain using the Limiting Dome Height (LDH) test. The test programme was carried out according to a design of experiments method so that the variability in the measured data could be quantified statistically. The relative safety factor for the two grades was then inferred from the statistical analysis.

\section{Variability in the forming process}

Col (2003) summarises a comprehensive list of parameters that influence formability, which were divided into the categories of 'material', 'process', 'tooling' and 'unpredictable causes'. Variability in the output may be minimised by ensuring that these parameters are kept the same between pressings and batches. However, this is difficult to enforce due to the inherent variability to the inputs of the process, such as gauge of the received material, as shown by Blumel et al. (1988) for several batches of material, or an increase to the temperature of the tooling as production progresses. Excessive variability can affect a part’s formability (Wang and Hancock, 1997) or dimensional stability (Zhou and Cao, 1994).

There is clearly a need to control variability to sensitive processes but this depends on how the performance of the processes is assessed. Wang and Hancock (1997) and Zhou and Cao (1994) looked at the industrial manufacture of door inner panels and came to different conclusions as to what should be controlled. Wang and Hancock (1997) concluded that to prevent splitting in their process, blankholder load, quantity of lubricant that is applied to the blanks and the surface roughness of the steel blanks were parameters that had to be controlled. Zhou and Cao (1994), however, concluded that controlling tooling velocity was 
important in ensuring dimensional stability. In calculations of springback, de Souza and Rolfe (2008) found that, for their simple geometry, material properties such as yield strength and the strain hardening index ( $n$-value) are important in controlling dimensional stability. The results of the above studies were based on the Design of Experiment (DoE) method.

Ayres et al. (1979) examined the occurrences of stretch failure in a press shop for five parts over a period of two years. In parts where failure occurred, the strain path was generally found to be in plane strain and correlated well to LDH tests that were carried out on the received batches of material. This was due to two reasons. Firstly, the LDH test is designed to replicate the plane strain path and secondly, it was sensitive to the variability in the mechanical properties of the materials that were used. The study illustrated the importance of the plane strain path and the effect of material variability in this strain path.

Thompson (1993) proposed an LDH test standard and felt that the 'consensus among stamping engineers is that approximately $85 \%$ of all fractures in automotive panels occur in plane strain'. The plane strain path is an important one because limit strains are a minimum along this path and this causes parts to be susceptible to failure through variability. Several material properties influence this limit but calculations based on load instability analysis (Hosford and Caddell, 1990) and the Marciniak-Kucynski failure model (Graf and Hosford, 1990) show that in plane strain, the hardening behaviour of a material, whether it is strain or strain-rate hardening, is particularly important. Variability of these properties can therefore affect the formability of the part.

Material parameters are not alone in influencing formability. A blank is shaped through contact with a set of tooling and its formability is also affected by friction that is generated through the contact. Friction is usually beneficial in blankholders, where it controls the rate of flow of material into a die, but it can be detrimental if it leads to strain concentrations (Ghosh, 1977) that cause premature failure. Variability to the frictional contact can thus lead 
to variable formability. However, materials with high $n$-values can counteract this tendency to form strain concentrations by spreading the concentration over a wider volume and reducing variability.

Haar (1996) and Schey (1983) summarised the factors that influence the frictional forces in the contact region and the level of the friction coefficient, $\mu$. These include the pressure within the contact, the quantity of lubricant used, the type of lubricant, the surface roughness that acts to preserve the lubricant within the contact region and the local temperature. The friction mechanism is regarded as complex because of the number of factors that affect it and their interactions (Haar, 1996). As a result, its effect on formability is generally better understood in simple shapes such as the LDH test, where a hemispherical punch is used to deform material in plane strain. Fischer and Schey (1992) described how an effective lubricant and suitable punch surface roughness are able to increase formability by allowing a greater volume of material to deform in LDH tests. The effect is similar to that of a material possessing a high $n$-value. Ayres (1983) found that changing the frictional contact condition can also change the strain path of the test, which may affect the material's formability.

\subsection{Choice of parameters}

The objective of this study was to understand the effect of variability on the press formability of AA6111-T4 and AA5754-O. Recognising the complexity of the press forming process, the problem was simplified to a study of the plane strain path, which accounts for the majority of failures in industry. To quantify the effect of variability, a series of LDH tests were conducted according to the DoE method that allowed a statistical analysis of the data and hence a discussion of the relative safety margins to be used for the two grades of material. Various aspects of the test method have been widely studied and its response to material properties and process parameters have been analysed and quantified. Ghosh (1975) first proposed the test to investigate the effect of lateral strains during pure stretching. His 
suggestion that the material should be clamped to prevent draw-in made the test repeatable and robust. Ayres et al. (1979) used the LDH test in an industrial environment and found that LDH results correlated well to press formability in an industrial environment. Graf and Izworski (1993) and Izworski and Graf (1991) built on this work and discussed aspects of the test that were important to control in order to ensure 'stability' in an industrial environment. They investigated the effects of temperature, tool cleanliness, lubrication and material properties on industrial LDH results. As a result of these investigations, the LDH test is regarded as a robust and repeatable test for the plane strain path.

Of the parameters that were chosen for this study, particular emphasis was placed on the effect of temperature because the temperature rise during serial production and its effect on formability is not well understood. Temperature increases during forming because plastic and frictional work is dissipated as heat. Newby (1981) estimated the temperature rise when pressing low carbon steels can be as high as $200^{\circ} \mathrm{C}$ but Blumel et al. (1988) measured only a $2{ }^{\circ} \mathrm{C}$ temperature rise during the serial production of a steel part using a thermocouple embedded within their tooling. Blumel et al. (1988) concluded that such a small rise could be ignored but the obvious criticism of measuring temperature with a thermocouple is that it records local temperatures, which may not be representative of the temperature in other areas of the tool. Graf and Izworski (1993) studied the effect of temperature on the LDH test and found that if the punch temperature varied from $40^{\circ} \mathrm{C}$ and $75^{\circ} \mathrm{C}$, $\mathrm{LDH}$ measurements varied by up to $10 \%$ in their experiments. Izworski and Graf (1991) found a similar response and showed that the fracture point in their samples shifted towards the pole or the highest point of the sample. Graf and Izworski (1993) and Izworski and Graf (1991) speculated that temperature impacts formability by altering the viscosity of the lubricant and material properties. 
Groche et al. (2008) attempted to explain the temperature rise in a strip draw test that involved a strip being pulled, under tension, through a set of tooling and around a $90^{\circ}$ bend. They created a model that consisted of the relevant forces acting on the strip as well as the heat generation and conduction mechanisms thought to act between the strip and tooling. Heat was assumed to be generated through frictional contact with tooling and through plastic deformation during the bending-unbending sequence as it flowed around the $90^{\circ}$ bend. Using their two dimensional model, the authors showed that the location of greatest tool wear corresponded to a local temperature peak. They speculated that increased tool temperature accentuates wear. Pereira et al. (2010) modelled a channel forming tool using a finite element model to calculate the potential temperature rise in the tool when forming parts out of advanced high strength steels and its effects. They found that for some grades, tool temperature can rise to around $130^{\circ} \mathrm{C}$ and this tended to coincide with areas of high contact pressure and wear between the blank and the die. The generated heat was found to quickly conduct into the bulk of the tool material when contact was relieved.

The studies of Groche et al. (2008) and Pereira et al. (2010) illustrate particularly the influence of geometry and contact pressure on tooling temperature during a single operation. However, during serial production, repeated processing of material by the tooling will result in a periodic input of heat into the tools. To our knowledge, it is not known how this successive addition of heat affects the temperature of the tooling and its formability and wear.

The other parameters that were investigated in this study were on the basis that they significantly influenced the forming process, they were of interest to industry and that it was possible to vary them in a controlled manner so that their effect could be measured. These were overall material properties, punch surface roughness, quantity of lubricant and gauge. The effect of overall material properties was tested rather than individual properties because individual properties are interlinked and could not be altered without changes to other 
properties. Material properties were changed using simple heat treatment schemes that mimicked the potential variabilities in the rolling process that is used to manufacture the sheet material. The effect of punch surface roughness was investigated because the surface condition of industrial tooling may be specified and can change over time through wear. Likewise, the quantity of lubricant was investigated because it can be controlled within a press-shop. Finally, gauge was investigated because of its effect on forming limits (Hosford and Caddell, 1997).

\subsection{Materials tested}

The investigation was carried out for two automotive grade aluminium alloys: AA6111-T4 and AA5754-O. AA6111-T4 is a solution heat treated grade that was tested with the MP404 mineral oil lubricant, while AA5754-O was tested with the ALO70 wax lubricant. The chemical composition of the grades and the lubricants are given in the table below.

\begin{tabular}{l|llllllll} 
Grade & $\mathrm{Si}$ & $\mathrm{Fe}$ & $\mathrm{Cu}$ & $\mathrm{Mn}$ & $\mathrm{Mg}$ & $\mathrm{Cr}$ & $\mathrm{Zn}$ & $\mathrm{Ti}$ \\
\hline AA5754-O & Max 0.4 & Max 0.4 & Max 0.1 & Max 0.5 & 2.6-3.6 & Max 0.3 & Max 0.2 & Max 0.15 \\
AA6111-T4 & 0.6-1.1 & Max 0.4 & 0.5-0.9 & 0.1-0.45 & 0.5-1.0 & Max 0.1 & Max 0.15 & Max 0.1
\end{tabular}

Table 1 Chemical composition (\% weight) of the alloying components of the grades tested

\begin{tabular}{l|lcc} 
Lubricant & Chemical composition & Density $\mathrm{kg} / \mathrm{m}^{3}$ & $\begin{array}{l}\text { Viscosity at } \\
50^{\circ} \mathrm{C} \mathrm{Pa} \mathrm{s}\end{array}$ \\
\hline AL070 wax lubricant & $\begin{array}{l}\text { Ethylene Glycol Dilaurate (>65\%), Ethylene } \\
\text { Glycol Monolaurate (<25\%) } \\
\text { Mineral oil, solubiliser, soap, fatty acid ester }\end{array}$ & 950 & 0.0045 \\
$\begin{array}{l}\text { Geroform MP404 deep } \\
\text { drawing oil }\end{array}$ & 940 & 0.032
\end{tabular}

Table 2 Chemical composition of the lubricants used in the tests

The shear viscosity of AL070 and MP404 was measured with a cone and plate apparatus and the nature of this test is described by Barnes (2000). The apparatus was mounted on a Kinexus Ultra rheometer and the lubricants were tested over a range of temperatures. The viscosity of AL070 could not be tested below $40^{\circ} \mathrm{C}$ as it gradually solidifies from $47^{\circ} \mathrm{C}$ to $40^{\circ} \mathrm{C}$ (Accordis, 1999). Two observations may be made of results of the measurements 
(Fig.1). The first is that, at $50^{\circ} \mathrm{C}, \mathrm{AL} 070$ has a viscosity that is an order of magnitude lower than that of MP404 and the second is that the viscosity of MP404 increases from 0.032 Pa s to $0.21 \mathrm{~Pa}$ s as temperature is reduced from $50^{\circ} \mathrm{C}$ to $20^{\circ} \mathrm{C}$.

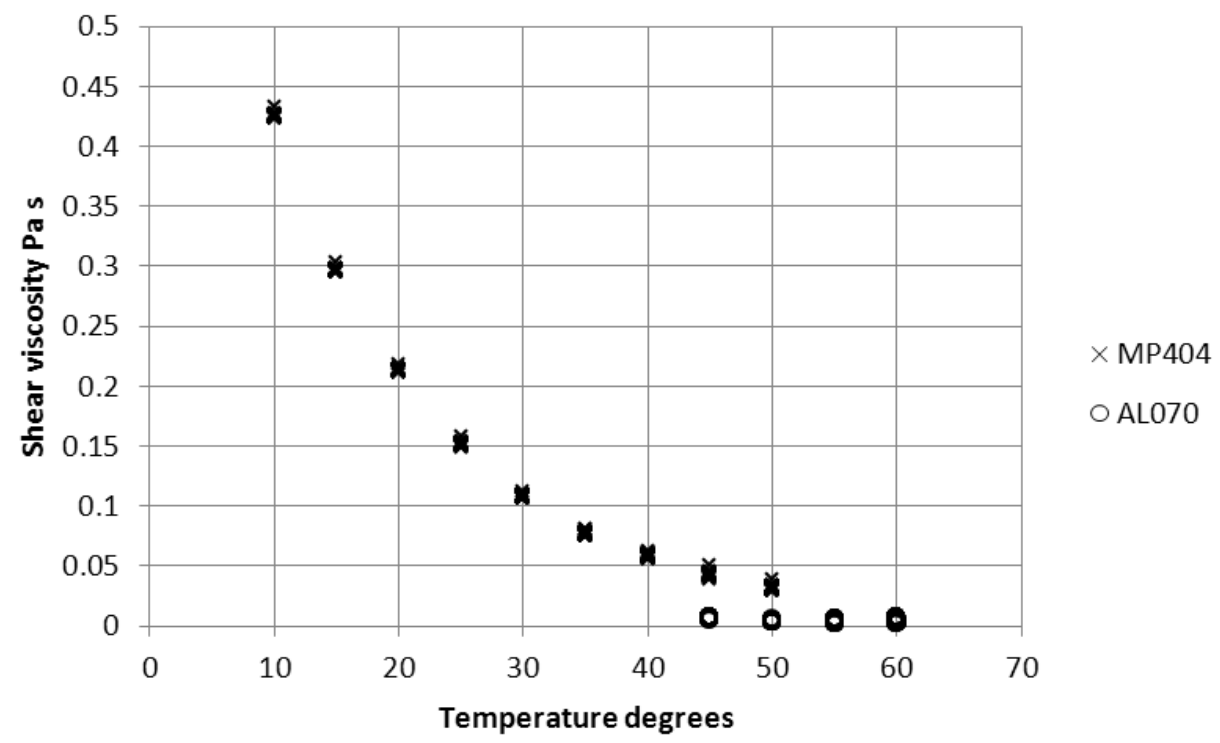

Fig.1 Variation of shear viscosity with temperature for MP404 and AL070

\subsection{Measuring formability with the Limiting Dome Height Test}

Formability was measured using the LDH test and a schematic diagram of the test arrangement is shown in Fig.2. Three tools make up the apparatus: a punch, die and blankholder. The blankholder incorporates locking beads to prevent material draw-in so that deformation occurs solely in stretch. The punch is $100 \mathrm{~mm}$ in diameter and the limiting dome height was taken as the point where the load peaked. To ensure that the samples deformed in plane strain, sample widths were varied until measured strains indicated plane strain deformation. 


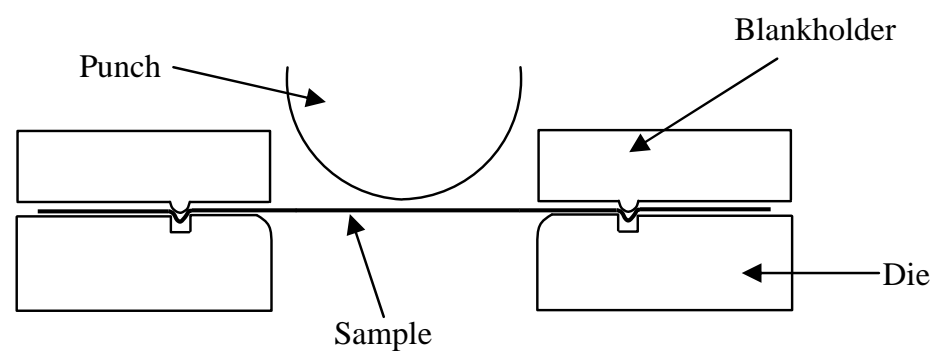

Fig.2 Schematic diagram of the LDH apparatus

In the experiments carried out in this study, the die and blankholder were placed on the base of an Instron 5800 tensile tester (Fig.3) while the punch was attached to the end of a loadcell which was securely attached to the Instron's crosshead. The loadcell capacity was $100 \mathrm{kN}$ (manufacturer's stated measurement error $\pm 0.128 \mathrm{kN}$ ), which was sufficiently high to test the two grades to failure. The crosshead was screw-driven and its displacement, velocity and termination were controlled using Instron’s Bluehill software. Test samples were mechanically clamped between the blankholders with six bolts that were tightened using a torque wrench to ensure sufficient and even distribution of force around the blankholder.

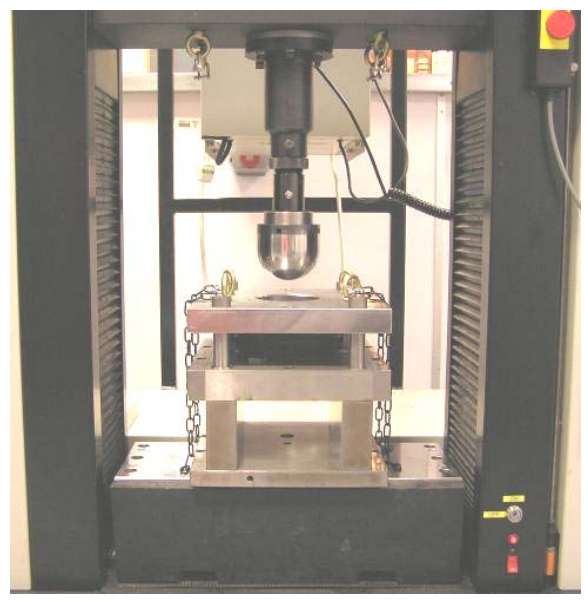

Fig.3 Experimental setup showing LDH tooling installed on an Instron 
Load-displacement plots were recorded on a PC during the tests and final strains in the sample were measured with the circle grid analysis method. Prior to the tests, the samples were marked with a fine pattern of uniformly-spaced dots using an electrochemical etch method. Strains were estimated by measuring the displacement of the dots after the test using the GOM Argus photogrammetry system, which provided a full field view of strains in the samples. The total error of the measurement was estimated from the analysis of 17 samples in the unstrained state. This was found to be \pm 0.017 true strain.

\subsection{Measuring the Temperature of Pressed Parts}

To ascertain the extent of temperature rise during serial production, an industrial trial was carried out along an automotive stamping line, which was based in Birmingham, United Kingdom, and equipped with a 2000 ton hydraulic draw press. The trial consisted of measuring the temperature of three part geometries just after the drawing phase. Measurements were carried out using an infrared camera because it is a non-contact technique that provides a full-field view of part temperature (Beattie, 1971). Thus, the measurements did not interfere with production.

Barber (1978) pointed out that a disadvantage of the method is that it is susceptible to stray, reflected radiation. In general, an infrared camera measures the radiation from three sources: the emission from the object of interest, reflected emissions from surrounding sources and emissions from the atmosphere (Nelkon and Parker, 1982). Reflected emission is radiation from surrounding sources that reflect off the object and emissions from the atmosphere is radiation that is dissipated as a result of ambient temperature. These two effects were minimised to measure part temperature accurately.

Atmospheric radiation was relatively simple to account for within the camera that was used in this trial (FLIR, 2003). However, in the press shop, reflected radiation was a problem 
because of the numerous sources of radiation in the environment such as strong lighting and motors that operate the press and feed robots. The problem is compounded by the low emissivity of metals, which accentuates the effect of reflected emissions and results in overestimated temperature readings. For this reason, the temperature of the draw tooling could not be measured reliably because its polished surface was highly reflective and it was in close proximity to lighting and motors. Instead, temperature measurements were taken of the underside of parts immediately after the draw process.

Through a process of trial and error, it was found that the underside of the parts was well shielded from reflected emissions (Fig.4). At the point when the measurements were taken, the parts were held suspended about 500mm above a 300mm thick floor, which was in thermal equilibrium with the surrounding air $\left(18^{\circ} \mathrm{C}\right)$. To estimate the temperature of the tooling, it was assumed that negligible heat was lost from the time the part was removed from the tooling to the time at which the measurement was taken. Parts were removed from the tooling using a transfer robot and the time delay from the opening of the tooling to the point when the temperature of the part was recorded was a few seconds. For this reason, it was assumed that the measured temperatures reflected the state of the tooling.

The measurements were carried out with FLIR's ThermaCAM SC3000, which was equipped with a gallium arsenide detector. The detector was designed to detect radiation within the narrow wavelength range of $8-9 \mu \mathrm{m}$, which maximised the signal-to-noise ratio of the detector between $20^{\circ} \mathrm{C}$ and $100^{\circ} \mathrm{C}$ (measurement uncertainty $= \pm 1 \%$ ). The following considerations were made to ensure measurement accuracy:

1. The 'emissivity' of the two grades of material was determined separately

2. The radiation lost through absorption by atmospheric water vapour and the radiation emitted by the temperature of the surrounding atmosphere was accounted for within the software that accompanied the camera 
3. Radiation interference from surrounding sources, such as motors and lighting were minimised as far as possible.

The emissivity of the two grades were determined prior to the press shop measurements according to the manufacturer's instructions, (FLIR, 2003). As expected, the emissivities were low because of their reflective surfaces and were found to vary little between $30^{\circ} \mathrm{C}$ to $80^{\circ} \mathrm{C}$.

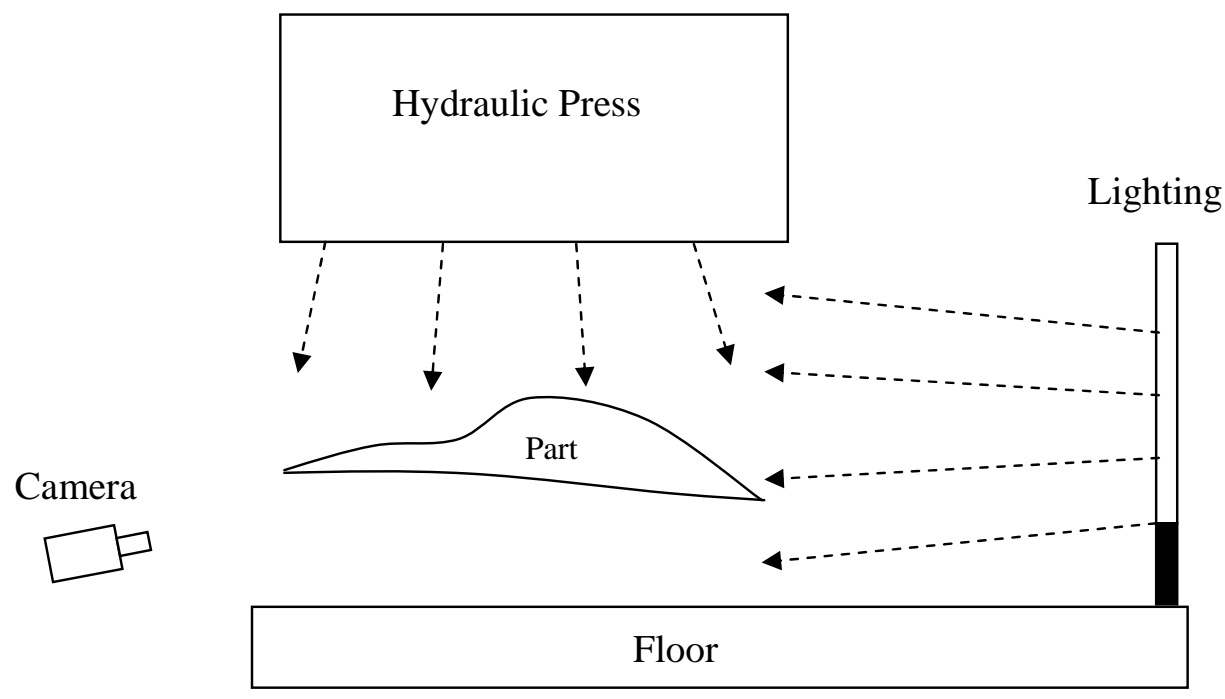

Fig.4 Camera position during the measurement of part temperature. The process flow is into

Start of response to

Reviewer \#1

The temperatures of three parts were measured. Parts A and B were front and rear fender outer panels made from 0.9mm gauge AA6111-T4 (Figs 5 and 6) and Part C was a structural floor cross-member made from 1.5mm gauge AA5754-O (Fig. 7). MP404 lubricant was used for Parts A and B while AL070 lubricant was used for Part C. Approximately 240 stampings were carried out per hour. The draw depths were about 215mm for Part A, 180mm for Part B and $100 \mathrm{~mm}$ for Part C. Temperatures were measured on the wall of the drawn shell where the strain was expected to be in plane strain. The intention was to start measuring when the tools were cold and to monitor the parts through a production run. However, the uncertainty of response to Reviewer \#1 
production scheduling meant that most measurements commenced mid-run. This had two effects. The first was that the quantity of data varied. The measurements for Part B were taken over a relatively shorter time compared to Parts A and C. The second was that it was not possible to measure the temperature profile of the tools as they warmed up at the start of production. However, the measurements of part A (Fig.5) commenced following a change of shift and the temperature of the first part was observed to be higher than $45^{\circ} \mathrm{C}$. No evidence was found of a transient temperature response after production re-started.

The temperature of the parts depended on the part being manufactured. The temperature for parts A and B were found to increase with time while the temperature of part C was relatively constant. At the end of the measurement session, part A and C were about $55^{\circ} \mathrm{C}$ while part $\mathrm{B}$, which was measured over a shorter period, was observed to be $32^{\circ} \mathrm{C}$. (Fig.5-7). All parts were above room temperature and this was likely to be due to material deformation and friction. From the data, it was not possible to separate the contributions made by these two factors. However, the gradual temperature increase seen in parts A and B suggests that, in some processes, heat accumulates in the tools as production progresses. The data in Figs.5-7 indicates that the highest absolute temperature recorded in the parts was $55^{\circ} \mathrm{C}$, although there was scatter in the data (for example, Fig.5). It was decided that formability should be tested with the $\mathrm{LDH}$ tooling at an upper temperature limit of $50^{\circ} \mathrm{C}$ because this was approximately the upper bound temperature that was observed in the AA6111-T4 and AA5754-O parts produced during the trial. 


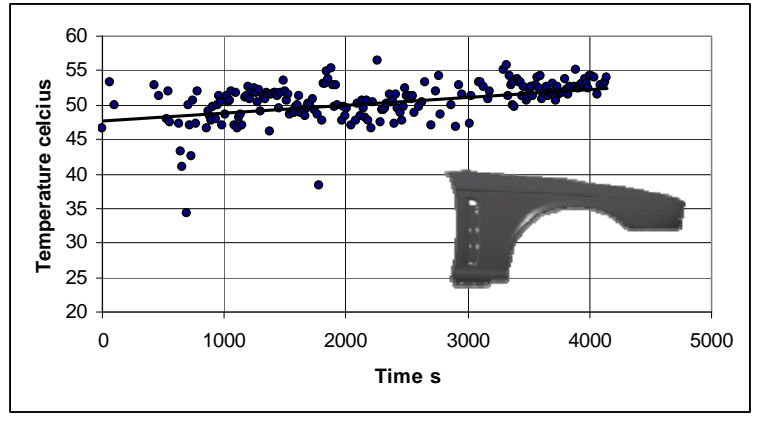

(a)Temperature data of Part A and a picture of the finished part

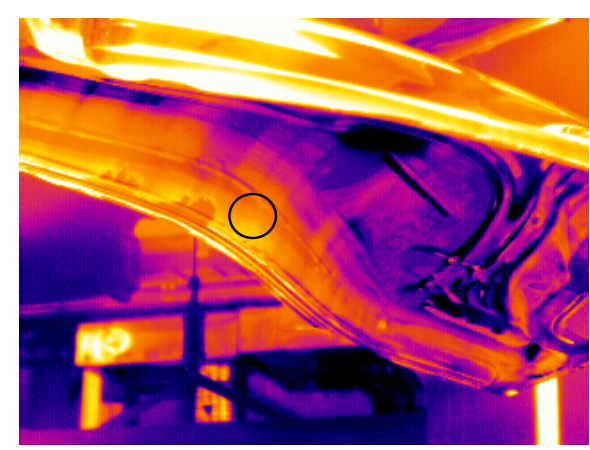

(b)Location where the measurement was made

Fig.5 Temperature of Part A during serial production. This part was made from AA6111-T4

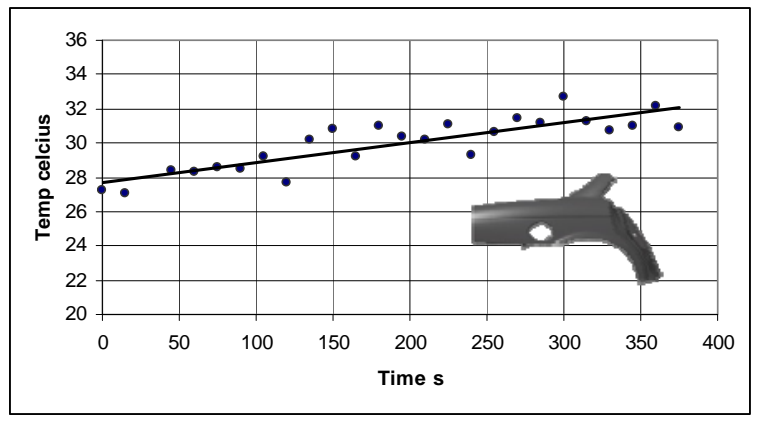

(c) Temperature data of Part B and a picture of the finished part

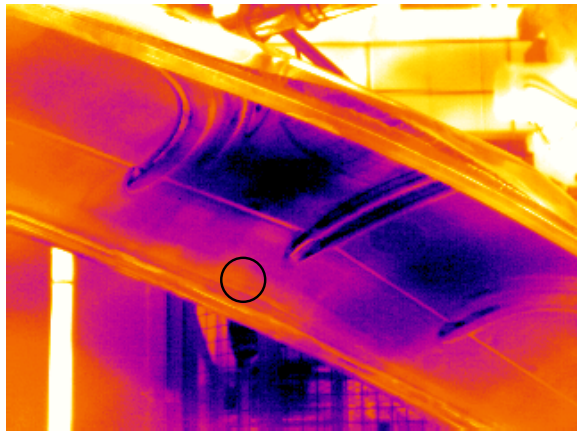

(d) Location where the measurement was made

Fig.6 Temperature of Part B during serial production. This part was made from AA6111-T4

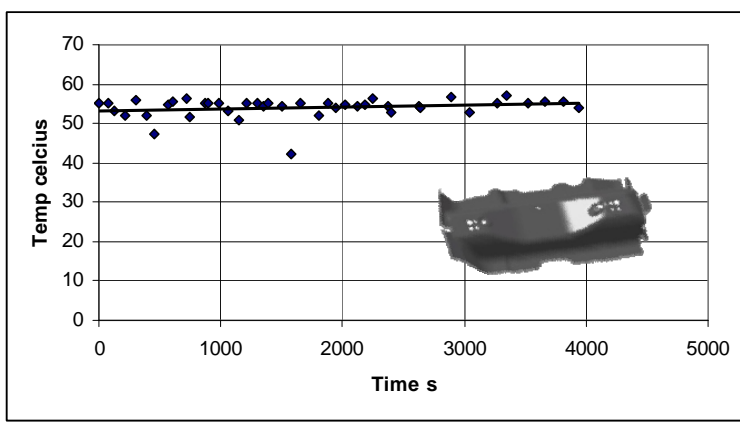

(e) Temperature data of Part C and a picture of the finished part

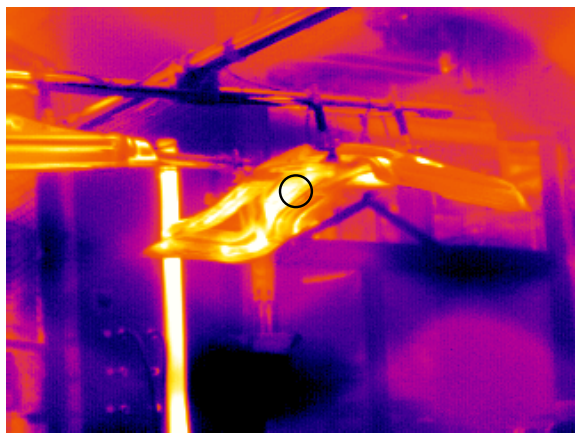

(f) Location where the measurement was made

Fig.7 Temperature of Part C during serial production. This part was made from AA5754-O 


\subsection{LDH Test programme}

The test programme was based on the DoE method (Funkenbusch, 2005) so that the LDH response could be quantified statistically. The forming response was assessed at two parameter levels and these were chosen, as far as possible, to reflect the range of values that occur within a press shop.

Material properties were altered using simple heat treatment schemes that approximate variations in the rolling process. For AA6111-T4, the final phase of the rolling process, as described by Burger et al. (1995), involves solution heat treating the material at around $500^{\circ} \mathrm{C}$ before it is quenched. The test samples of AA6111-T4 were therefore altered by heating the material at $200^{\circ} \mathrm{C}$ for 5 mins to simulate a condition where the quenching was delayed. It was expected that this promoted the age-hardening response through the precipitation of solute particles, as described qualitatively by Burger et al. (1995) for 6000 series alloys. The effect of the precipitation in the grain structure is to hinder the motion of dislocations plastic deformation and Polmear (1995) describes two ways, 'cutting' and 'bypassing', in which dislocations may be hindered. Macroscopically, this leads to a higher strength, but lower formability material. For AA5754-O, the material was further annealed at $350^{\circ} \mathrm{C}$ for $45 \mathrm{mins}$ to relieve residual stresses due to the tension leveller in the rolling process. The temperature and time settings were based on experimental data that was used by Go et al. (2003) to model the recrystallisation process of AA5754-O.

For AA6111-T4, heat treatment was carried out by heating as-received samples in an oven pre-set to $200^{\circ} \mathrm{C}$ for 5 minutes (Burger et al., 1995). Two repeat comparisons showed that yield stress increased from 143MPa to156MPa, while strain hardening dropped (Fig.8a). When the hardening was approximated by a power law, $\sigma \cdot F \Omega^{n}$, where $\sigma$ is stress, $\varepsilon$ is strain and $K$ is a constant, the hardening exponent, $n$, reduced from 0.26 to 0.23 over the range of 0.1 to 0.2 true strain. In a similar manner, some of the strains in as-received 
AA5754-O that were induced by the tension leveler during cold rolling were recovered to reduce its $\sigma_{y}$ by $112.3 \mathrm{MPa}$ to $104.3 \mathrm{MPa}$ and increase its $n$-value by 0.25 to 0.26 (Fig.8b). These levels reflect the variation seen in material property data that is received at press shops.

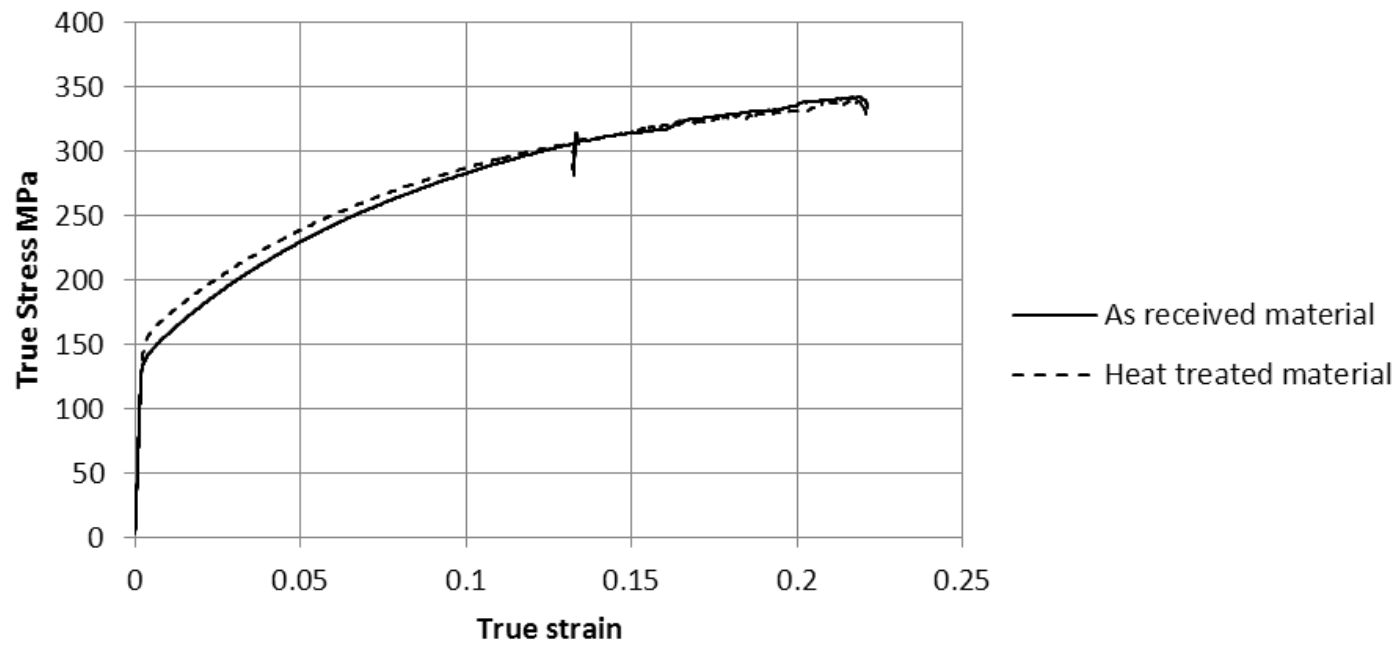

Fig.8a True stress-strain curves for as-received and heat treated AA6111-T4

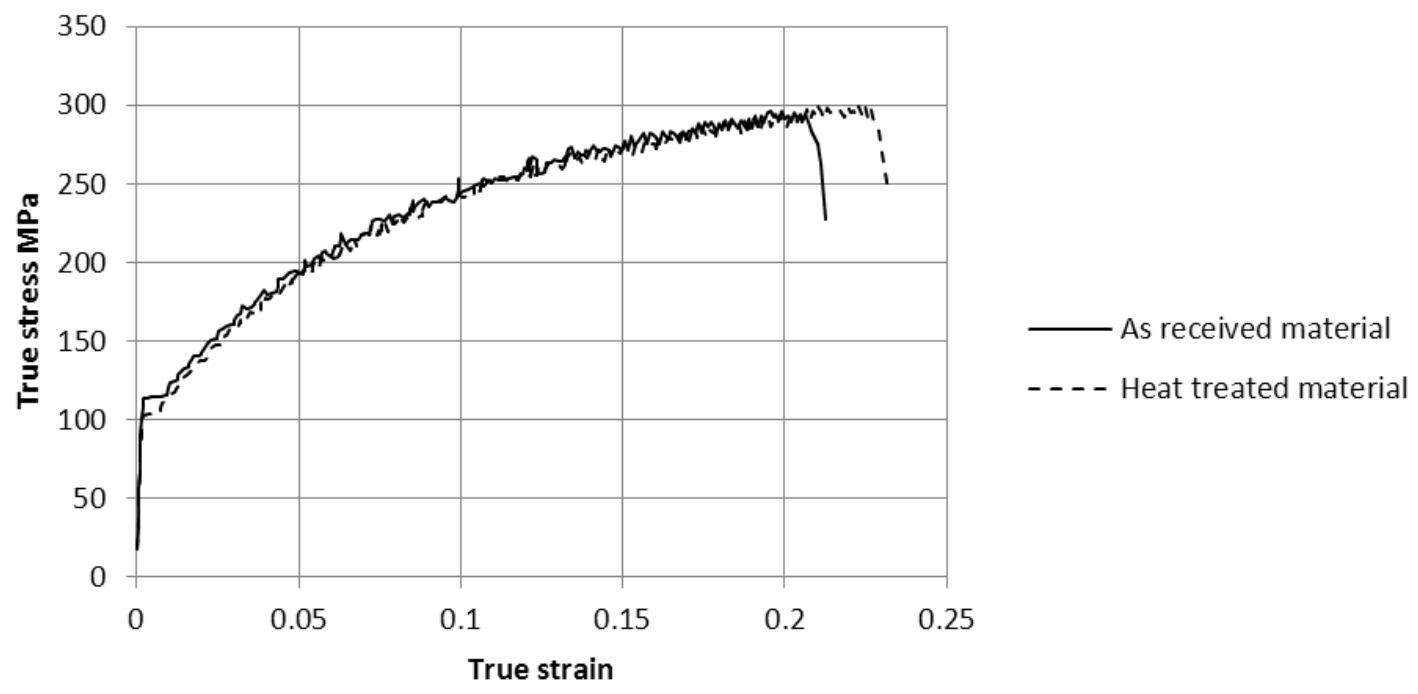

Fig.8b True stress-strain curves for as-received and heat treated AA5754-O

To test for the effect of surface roughness, the punch was polished to two levels of average 
surface roughness: $0.13 \mu \mathrm{m}$ and $0.3 \mu \mathrm{m}$. Thompson (1993) recommends a punch surface roughness of $0.13 \mu \mathrm{m}$ for a standard LDH test while the rougher $0.3 \mu \mathrm{m}$ finish was chosen because production tooling at press shops are generally finished with relatively coarse grit paper. The finish on the tooling was applied with lapping paste and the average surface roughness was verified with a Taylor Hobson Surtronic 25 surface texture measurement device.

The effect of the quantity of lubricant was tested at $1 \mathrm{~g} / \mathrm{m}^{2}$ and $2 \mathrm{~g} / \mathrm{m}^{2}$ to reflect the quantity of lubricant that is applied in production. For these experiments, the lubricant was applied to the LDH samples using a brush. The quantity and uniformity of the applied lubricant was checked for each sample with a Phund paint film gauge. This is a mechanical gauge that measures the thickness of a film. The lubricant weight was calculated using the density of the lubricants in Table 2.

The effect of die temperature on formability was based on the results presented in Fig.5-7 and was measured at two temperatures, $20^{\circ} \mathrm{C}$ and $50^{\circ} \mathrm{C}$. For tests carried out at $50^{\circ} \mathrm{C}$, the punch was soaked in an oven for two hours and replaced on the rig just before the test. The uniformity of the temperature along the surface of the punch was checked at three points with a thermocouple. At $50^{\circ} \mathrm{C}$, the material was not expected to have undergone a noticeable change since mechanical properties such as yield strength, elongation and strain hardening of both grades were shown by $\mathrm{Li}$ and Ghosh (2003) to change by about $10 \%$ from $20^{\circ}$ to $200^{\circ} \mathrm{C}$.

\subsection{Results for Limiting Dome Height Tests of AA6111-T4}

The LDH tests for AA6111-T4 were carried out according to a full factorial DoE. The estimated mean LDH response for AA6111-T4 was 24.66mm and the estimated standard deviation was $1.58 \mathrm{~mm}$. Table 3 presents the raw data for the LDH measurements for the 
various parameter combinations. Table 4 presents the results for the analysis of variance to identify the significance of the parameters on the LDH. This was carried out using the Statistical toolbox in Matlab v.2009. Interactions between parameters were found to be statistically insignificant and were therefore used in the estimate of the error in the experiments.

\begin{tabular}{|c|c|c|c|c|c|}
\hline Test & $\begin{array}{c}\text { Surface } \\
\text { roughness } \\
+1=0.13 \mu \mathrm{m} \\
-1=0.3 \mu \mathrm{m}\end{array}$ & $\begin{array}{l}\text { Quantity of } \\
\text { lube } \\
+1=2 \mathrm{~g} / \mathrm{m} 2 \\
-1=1 \mathrm{~g} / \mathrm{m} 2\end{array}$ & $\begin{array}{l}\text { Die temp } \\
+1=50^{\circ} \mathrm{C} \\
-1=20^{\circ} \mathrm{C}\end{array}$ & $\begin{array}{c}\text { Heat treatment } \\
+1=\text { heat treated } \\
-1=\text { no treatment }\end{array}$ & $\begin{array}{c}\text { LDH } \\
\text { Results } \\
(\mathrm{mm})\end{array}$ \\
\hline 1 & -1 & -1 & -1 & -1 & 25.84 \\
\hline 2 & -1 & -1 & -1 & +1 & 22.21 \\
\hline 3 & -1 & -1 & +1 & -1 & 25.93 \\
\hline 4 & -1 & -1 & +1 & +1 & 23.60 \\
\hline 5 & -1 & +1 & -1 & -1 & 25.89 \\
\hline 6 & -1 & +1 & -1 & +1 & 23.55 \\
\hline 7 & -1 & +1 & +1 & -1 & 24.64 \\
\hline 8 & -1 & +1 & +1 & +1 & 23.82 \\
\hline 9 & +1 & -1 & -1 & -1 & 26.49 \\
\hline 10 & +1 & -1 & -1 & +1 & 25.25 \\
\hline 11 & +1 & -1 & +1 & -1 & 27.00 \\
\hline 12 & +1 & -1 & +1 & +1 & 23.12 \\
\hline 13 & +1 & +1 & -1 & -1 & 24.99 \\
\hline 14 & +1 & +1 & -1 & +1 & 22.62 \\
\hline 15 & +1 & +1 & +1 & -1 & 26.83 \\
\hline 16 & +1 & +1 & +1 & +1 & 22.79 \\
\hline $\begin{array}{l}\text { Change in } \\
\text { LDH (mm) }\end{array}$ & 0.45 & -0.54 & 0.11 & -2.58 & \\
\hline
\end{tabular}

Table 3 Test data for the LDH tests carried out on AA6111

\begin{tabular}{cccccc} 
Parameter & $\begin{array}{c}\text { Sum of } \\
\text { Squares }\end{array}$ & $\begin{array}{c}\text { Degree of } \\
\text { freedom }\end{array}$ & Mean Squares & F-ratio & p \\
\hline Surface & & & & & \\
Roughness & 0.811301022 & 1 & 0.811301 & 1.000219 & 0.33875 \\
Qty of Lube & 1.157953547 & 1 & 1.157954 & 1.427592 & 0.257284 \\
Tool Temp & 0.048764785 & 1 & 0.048765 & 0.06012 & 0.810821 \\
Heat Treatment & 26.61886663 & 1 & 26.61887 & 32.81728 & 0.000132 \\
\hline Error & 8.922357737 & 11 & 0.811123 & & \\
Total & 37.55924372 & 15 & Std dev $=1.58$ & &
\end{tabular}

Table 4 Analysis of variance for the parameters that were tested on AA6111-T4. Only main factor effects were considered. 


\subsection{Results for Limiting Dome Height Tests for AA5754-O}

For the AA5754-O tests, gauge size was introduced as an additional factor and assuming no interaction effects, a fractional design was adopted. The mean LDH response of AA5754-O was $28.33 \mathrm{~mm}$ and the standard deviation was $0.88 \mathrm{~mm}$. Table 5 presents the raw data for the LDH measurements for the various parameter combinations and Table 6 presents the analysis of variance to identify the significance of the parameters on the LDH.

\begin{tabular}{|c|c|c|c|c|c|c|}
\hline Test & $\begin{array}{c}\text { Surface } \\
\text { roughness } \\
+1=0.13 \mu \mathrm{m} \\
-1=0.3 \mu \mathrm{m}\end{array}$ & $\begin{array}{l}\text { Quantity of } \\
\text { lube } \\
+1=2 \mathrm{~g} / \mathrm{m} 2 \\
-1=1 \mathrm{~g} / \mathrm{m} 2\end{array}$ & $\begin{array}{c}\text { Die temp } \\
+1= \\
\text { 50degrees } \\
-1= \\
\text { 20degrees } \\
\end{array}$ & $\begin{array}{l}\text { Heat treatment } \\
+1=\text { heat treated } \\
-1=\text { no treatment }\end{array}$ & $\begin{array}{c}\text { Gauge } \\
+1= \\
1.25 \mathrm{~mm} \\
-1= \\
1.80 \mathrm{~mm}\end{array}$ & $\begin{array}{c}\mathrm{LDH} \\
\text { results } \\
(\mathrm{mm})\end{array}$ \\
\hline 1 & -1 & -1 & -1 & -1 & +1 & 27.04 \\
\hline 2 & -1 & -1 & -1 & +1 & -1 & 27.04 \\
\hline 3 & -1 & -1 & +1 & -1 & -1 & 28.67 \\
\hline 4 & -1 & -1 & +1 & +1 & +1 & 29.79 \\
\hline 5 & -1 & +1 & -1 & -1 & -1 & 27.96 \\
\hline 6 & -1 & +1 & -1 & +1 & +1 & 28.58 \\
\hline 7 & -1 & +1 & +1 & -1 & +1 & 29.04 \\
\hline 8 & -1 & +1 & +1 & +1 & -1 & 29.50 \\
\hline 9 & +1 & -1 & -1 & -1 & -1 & 27.42 \\
\hline 10 & +1 & -1 & -1 & +1 & +1 & 27.83 \\
\hline 11 & +1 & -1 & +1 & -1 & +1 & 27.75 \\
\hline 12 & +1 & -1 & +1 & +1 & -1 & 28.42 \\
\hline 13 & +1 & +1 & -1 & -1 & +1 & 27.79 \\
\hline 14 & +1 & +1 & -1 & +1 & -1 & 28.38 \\
\hline 15 & +1 & +1 & +1 & -1 & -1 & 28.25 \\
\hline 16 & +1 & +1 & +1 & +1 & +1 & 29.84 \\
\hline $\begin{array}{l}\text { Change } \\
\text { in LDH } \\
(\mathrm{mm})\end{array}$ & -0.24 & 0.67 & 1.15 & 0.68 & 0.25 & \\
\hline
\end{tabular}

Table 5 Test data for the LDH tests carried out on AA5754-O 


\begin{tabular}{cccccc} 
Parameter & Sum of Squares & dof & Mean Square & F-ratio & p \\
\hline Surface Roughness & 0.239466 & 1 & 0.239466 & 1.104603 & 0.317993 \\
Qty of Lube & 1.806974 & 1 & 1.806974 & 8.335171 & 0.016188 \\
Tool Temp & 5.309257 & 1 & 5.309257 & 24.49042 & 0.00058 \\
Heat Treatment & 1.871308 & 1 & 1.871308 & 8.631926 & 0.014836 \\
Gauge & 0.258397 & 1 & 0.258397 & 1.191927 & 0.300546 \\
\hline Error & 2.167891 & 10 & 0.216789 \\
Total & 11.65329 & 15 & Std dev $=0.88 m m$ \\
Table 6 Analysis of variance for the parameters that were tested on AA5754-O. Only \\
main factor effects were considered.
\end{tabular}

\section{Discussion}

The analysis of variance for AA6111-T4 (Table 4) shows that the only effect on formability (LDH) is due to material property changes while for AA5754-O (Table 6), the significant effects were due to tool temperature, quantity of lubricant used in the tests and changing material properties. The mean squares data in Table 6 suggests that AA5754-O was most sensitive to changes to tooling temperature, followed by material changes brought about by the heat treatment and then by the quantity of lubricant.

\subsection{Material property}

The response of AA6111-T4 and AA5754-O to changes in material properties reflects findings in the literature that formability is particularly influenced by the strain hardening properties of a material (Section 2). For AA6111-T4, the reduction in the $n$-value through the heat treatment resulted in lower formability, while for AA5754-O, the increase in the $n$-value through heat treatment resulted in greater formability (Section 3.3). The extent of the effect on AA6111-T4 was found to be greater than that for AA5754-O, based on the p-values of the analysis of variances. This was probably because the change in the $n$-value for AA6111-T4 (0.26 to 0.23 ) was greater than that achieved for AA5754-O (0.25 to 0.26). 


\subsection{Quantity of lubricant}

The quantity of lubricant had an effect on AA5754-O alone: increasing lubricant quantity increased formability. Both materials were subjected to similar experimental conditions in terms of strain rates, temperature, tool surface roughness and weight of lubricant during the course of the experiments, and the effect may have been due to differences in the viscosities of the lubricant, the surface roughness of the sample material or the normal pressure acting in the contact region due to differences in the sample mechanical properties. To check if the quantity of lubricant that was applied had any effect on the strain path of the samples, the minor strain at the pole of the samples was examined. No effect was found and the change in formability could not be explained as arising through a change in strain path. The effect of the quantity of lubricant on formability was thus difficult to explain, especially since contact forces depend on numerous factors which interact such as the load applied to the contact, the evolving nature of the surfaces during plastic deformation and the evolving behaviour of the lubricant in the contact.

\subsection{Effect of temperature}

Changing tool temperature had a significant effect on AA5754-O. From measurements of the physical properties of AL070, it is known that the lubricant melts between $40^{\circ} \mathrm{C}$ to $47^{\circ} \mathrm{C}$ (Accordis, 1999) and that its viscosity is an order of magnitude lower than that of MP404 (Table 2). It is postulated that the change in phase of the lubricant as well as its low viscosity at $50^{\circ} \mathrm{C}$ altered the contact behaviour and thus the formability of AA5754-O. As a result, formability increased significantly from $20^{\circ} \mathrm{C}$ to $50^{\circ} \mathrm{C}$. It may thus be postulated that, the pressing of the AA5754-O part in Fig.6 may have benefitted from the use of AL070 and may be unformable if its temperature was kept below $40^{\circ} \mathrm{C}$ through, say, a slower process that 
allows a greater dissipation of heat into the tools.

Changing tool temperature did not have an effect on the formability of the AA6111-T4 samples. However, the strain distributions in the low temperature samples were qualitatively different to those of the higher temperature samples. Strain profiles were compared along the centre-line of the samples, as shown in Fig.9.

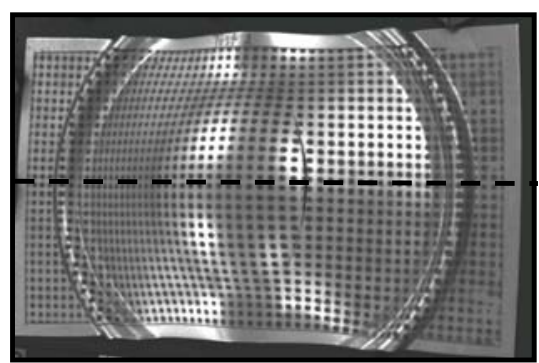

(a)

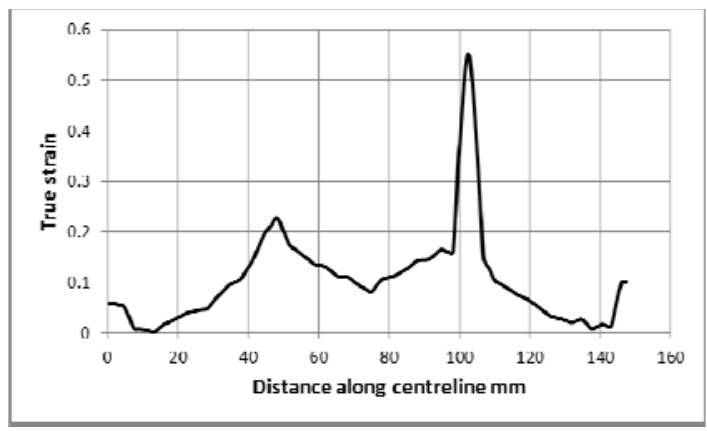

(b)

Fig.9 (a) Shows the centreline of a sample of AA6111-T4 (b) Shows the strain distribution along the centreline of the sample

The strain distribution in the higher temperature samples were observed to contain strain concentrations compared to the low temperature samples (Fig.10). The origin of these strain concentrations is not known but may be due to a stick/slip mechanism. Such strain concentrations could have precipitated the failures of the $50^{\circ} \mathrm{C}$ samples. 


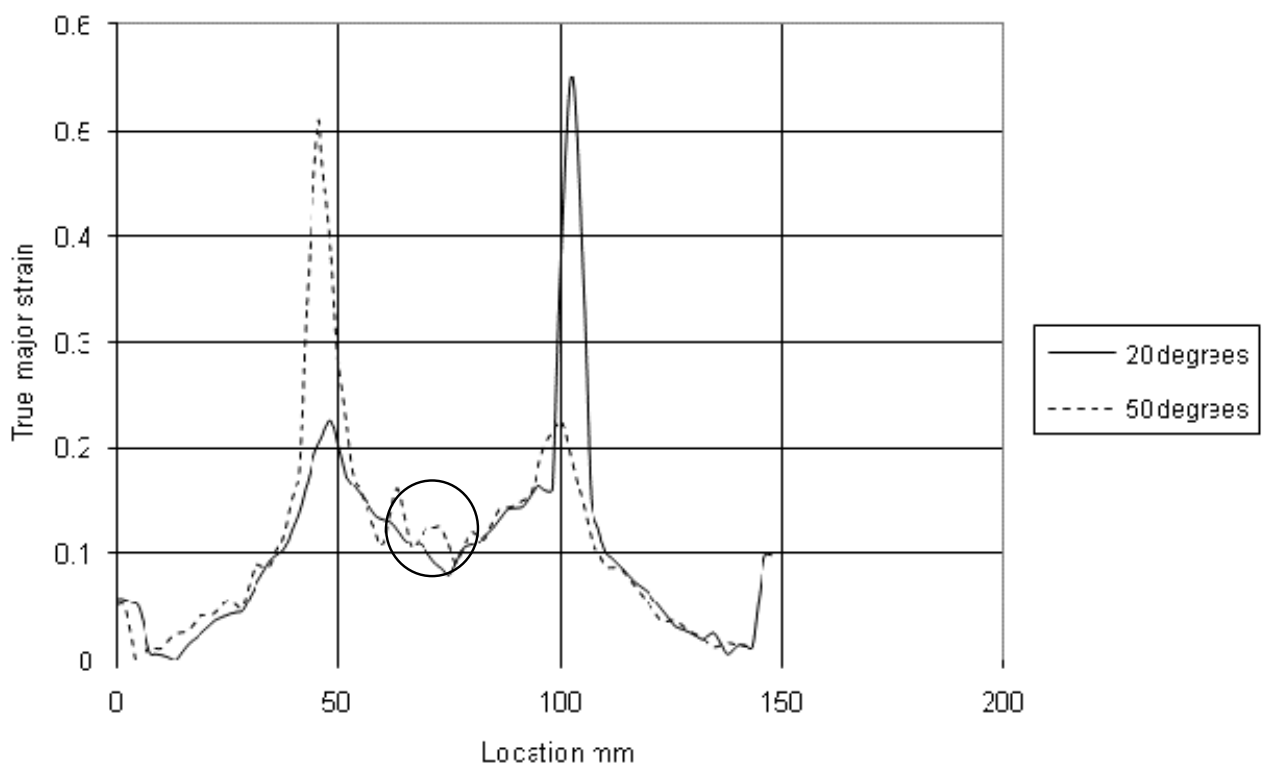

Fig.10 Strain distribution for AA6111-T4 samples at two test temperatures. The circled region shows the difference in strain distribution typically seen between $20^{\circ} \mathrm{C}$ and $50^{\circ} \mathrm{C}$ samples

\subsection{Springback}

The results from the LDH tests illustrate that material and process variations affect formability. Strain analysis of the samples shows that the tests also affect the strain distribution within the samples. Although springback is not the main focus of this work, it is interesting to consider the effect of strain distribution on springback. Springback is the elastic recovery of internal stresses after a part is formed and is a problem because it affects the dimensional accuracy of a part. According to Asnafi (2001), springback is caused when forming stresses are non-uniformly distributed and when the forming process induces significant bending moments in the part.

An examination of strain profiles of the tested parts suggests that material and process variation can change the strain distribution in the samples. Strain profiles of the samples 
along the centreline were studied and the distance between peaks was measured to give an indication of the strain distribution in the samples. An example of this measurement is shown in Fig.11. Two difficulties caused uncertainty in locating the peaks accurately. The first was the low density of points in the peaks associated with the physical crack, which made it difficult to locate the peak accurately. The second was that, in some samples, the peak associated with the un-cracked side rose very gradually, making it difficult to estimate the location of its peak. As a result the data presented in this section is an indication rather than a definitive account of the strain distribution in the samples.

Distance between peaks

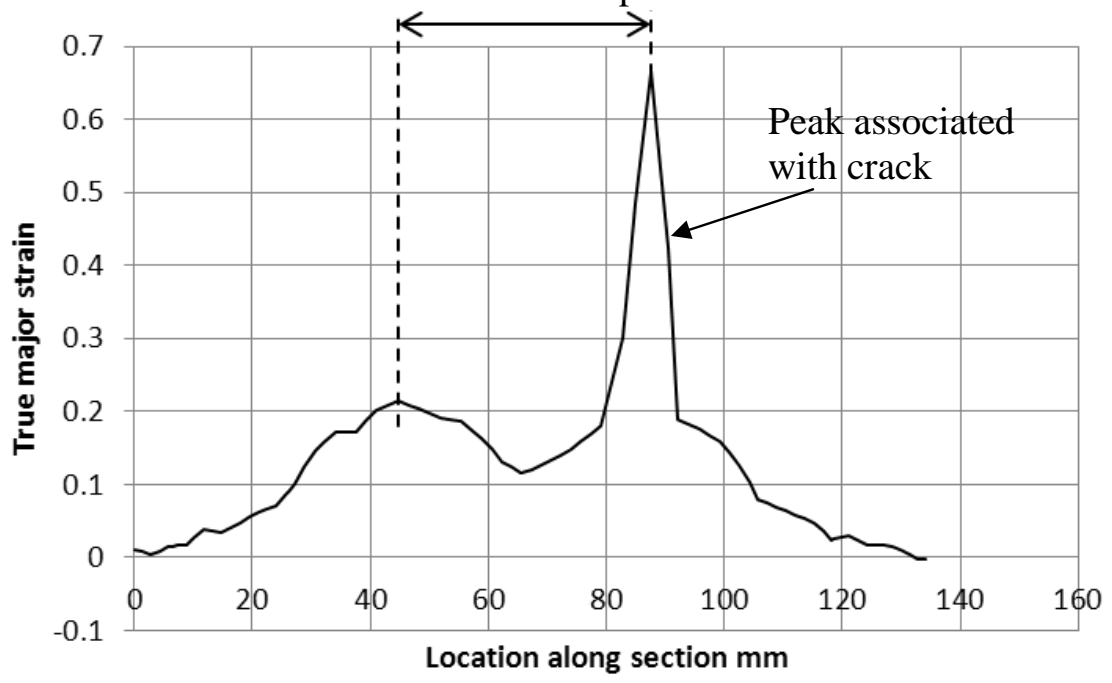

Fig.11 Schematic diagram of the strain distribution along the centreline of a AA5754-O sample. The diagram shows how the distance between the peaks was measured.

Material and process influences were examined by carrying out an analysis of variance on the distance between the peaks. Table 7 shows the results for AA6111-T4 while Table 8 shows the results for AA5754-O. 


\begin{tabular}{cccccc} 
Parameter & Sum of Squares & dof & Mean Square & F-ratio & $\mathrm{p}$ \\
\hline Surface Roughness & 2.175625 & 1 & 2.175625 & 0.42147 & 0.529526 \\
Quantity Lubricant & 1.380625 & 1 & 1.380625 & 0.26746 & 0.61528 \\
Tool Temperature & 4.305625 & 1 & 4.305625 & 0.834102 & 0.380671 \\
Heat Treatment & 58.90563 & 1 & 58.90563 & 11.41142 & 0.006163 \\
\hline Error & 56.78188 & 11 & 5.161989 & & \\
Total & 123.5494 & 15 & & & \\
\hline
\end{tabular}

Table 7 Analysis of variance for the distance between peaks of AA6111-T4 samples.

Only main factor effects were considered.

\begin{tabular}{cccccc} 
Parameter & Sum of Squares & dof & Mean Square & F-ratio & $\mathrm{p}$ \\
\hline Surface Roughness & 2.975625 & 1 & 2.975625 & 0.099781 & 0.758587 \\
Quantity Lubricant & 352.5006 & 1 & 352.5006 & 11.8203 & 0.006352 \\
Tool Temperature & 39.37563 & 1 & 39.37563 & 1.320372 & 0.277267 \\
Heat Treatment & 2.805625 & 1 & 2.805625 & 0.09408 & 0.765344 \\
Gauge & 7.155625 & 1 & 7.155625 & 0.239948 & 0.634812 \\
\hline Error & 298.2163 & 10 & 29.82163 & & \\
Total & 703.0294 & 15 & & & \\
\hline
\end{tabular}

Table 8 Analysis of variance for the distance between peaks of AA5754-O samples. Only main factor effects were considered.

The analysis of variance for AA6111-T4 and AA5754-O indicates that significant changes to strain distribution occurred during the LDH tests. For AA6111-T4, the strain distribution of the samples was significantly affected by heat treating the samples alone while for AA5754$\mathrm{O}$, the strain distribution was significantly affected by increasing the quantity of lubricant. The change in strain distribution implies that varying material and process parameters could have an impact on springback behaviour. However, a test that explicitly measures dimensional accuracy, such as the stretch tests carried out by Asnafi (2001), will give a better indication of springback behaviour.

\subsection{Safety Factors}

To understand the relative safety factors that may be employed on AA6111-T4 and AA5754$\mathrm{O}$, the overall forming sensitivities of both grades was examined. The sensitivities may be visualised using normal probability plots of the LDH data (Fig 12). 


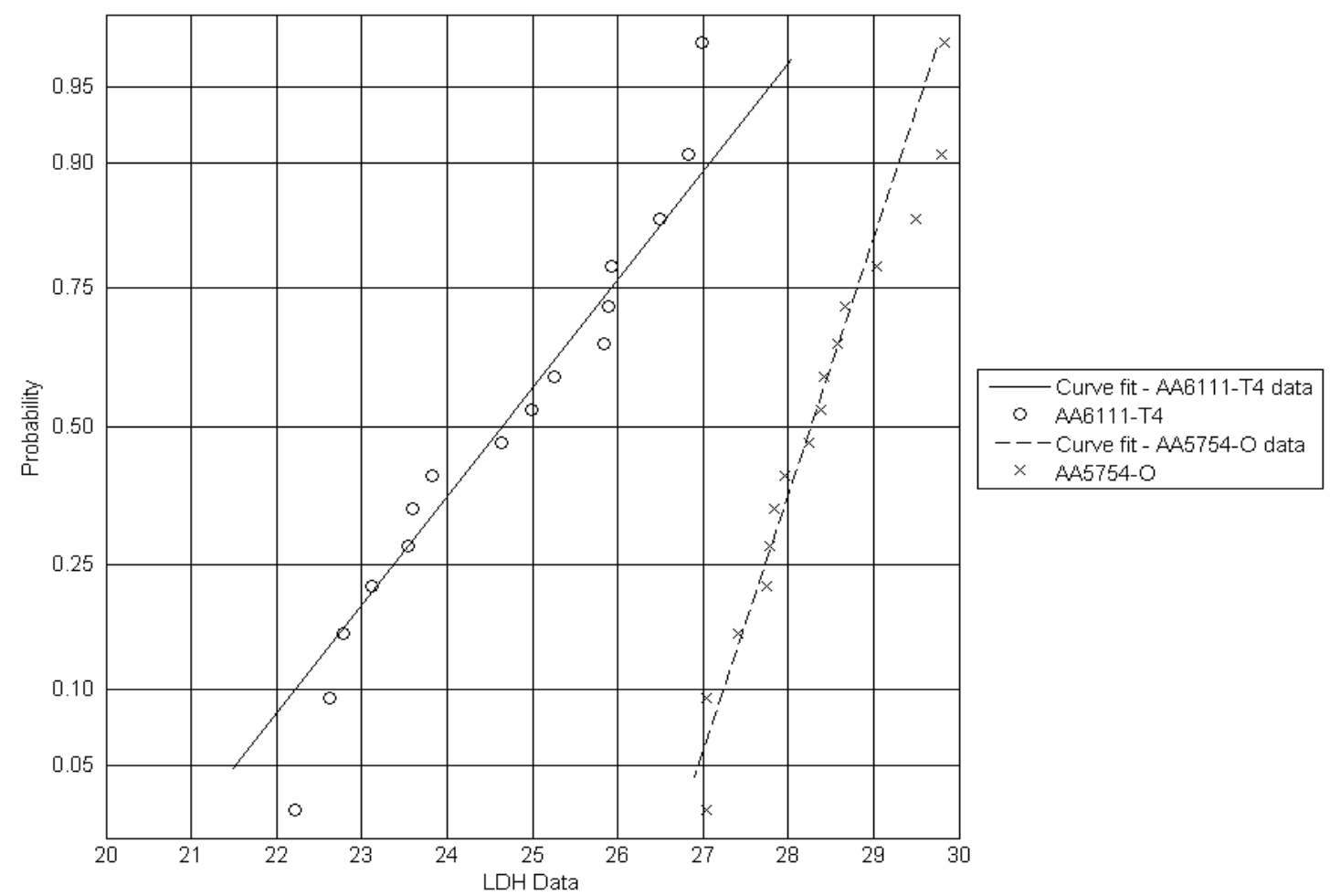

Fig.12 Normal probability plot for the LDH data of AA6111-T4 and AA5754-O

Fig.12 shows that, excluding some outliers, the LDH data are linearly distributed on a normal probability plot, indicating that the data is normally distributed. The slope of the AA5754-O distribution is steeper than that of the AA6111-T4 distribution showing the relatively higher dispersion in the AA6111-T4 data. This is reflected in the standard deviation of the grades, which was $1.58 \mathrm{~mm}$ for AA6111-T4 and 0.88mm for AA5754-O. A safety factor may be estimated from the probability of failure of the two grades. If a lower than $5 \%$ probability of failure is required, the threshold $\mathrm{LDH}$ value for AA6111-T4 will be $21.5 \mathrm{~mm}$ and the threshold LDH value for AA5754-O will be $27 \mathrm{~mm}$. If the safety factor is then defined as the difference between the $5 \%$ probability of failure and the mean responses of the grades, the normalised safety factors are 12.9\% for AA6111-T4 and 4.6\% for AA5754-O (based on mean). This illustrates that the relative safety factor of AA5754-O can be lower than that used for AA6111-T4. The actual margin of the safety used will also depend on factors that were 
not considered in this study. These factors include the forming response to other strain paths, errors in tool position in a press (Col, 2003) and the attitude that is adopted towards risk.

\section{Future work}

This work shows that AA6111-T4 and AA5754-O are sensitive to material and process parameters. However, a disadvantage of the DoE method is that it does not provide an explanation of the underlying causes that bring about the changes in a response. One way of explaining the LDH responses is to model the experiments using finite element models. Material property inputs for the models will be for as-received and heat treated materials and this will be used to define flow curves, yield criteria and forming limit curves. Coefficient of friction values will be less easy to define but can be done in two ways. First, they can be measured experimentally using a strip draw tests described by Schey (1983) for the different surface roughness, lubricant quantity and temperature conditions. Second, if coefficient of frictions values cannot be obtained through experimentation, the coefficient of friction in models may be fitted to experimental load-displacement and strain data from the LDH tests. The quality of the correlation to the experimental data could provide an insight into the mechanisms underlying the LDH responses. Subsequent models may then be made more sophisticated by incorporating the relevant heat transfer mechanisms.

\section{Conclusions}

This study set out to investigate the effect of material and process variations in the stamping process of AA6111-T4 and AA5754-O, with particular emphasis on the effect of tooling temperature. The temperature of parts that were manufactured in serial production was measured and was found to be between $28^{\circ} \mathrm{C}$ and $55^{\circ} \mathrm{C}$. The modest temperature rise is unlikely to have resulted in changes to the properties of the material but may have altered the properties of the lubricant. The other parameters that were investigated were changes to 
overall material properties, tooling surface roughness, lubricant quantity and gauge. The effects of the parameters were tested in plane strain using the LDH test. The mean response of AA5754-O was found to be higher than for AA6111-T4, implying that it was more formable than AA6111-T4. The standard deviation of the AA5754-O data was smaller than that for AA6111-T4. The lower dispersion in the AA5754-O data suggested that a smaller safety factor may be used in calculating the feasibility of parts that are made from it, since its formability was less susceptible to material and process variations.

Material properties were found to have an effect on the formability of both materials. For AA6111-T4, it was the only parameter that significantly affected its formability. AA5754-O was also found, in particular, to be affected by the temperature of the tooling. This was probably because the lubricant that was used, AL070, melts between $40^{\circ} \mathrm{C}$ and $47^{\circ} \mathrm{C}$, thus influencing its formability.

\section{Acknowledgements}

This work was carried out as part of the Premium Automotive Research and Development Programme, which was part funded by Advantage West Midlands. The authors would like to acknowledge the supply of material and tooling from Novelis and the helpful discussions and suggestions made by Dr Alan Carr. The ThermaCAM SC3000 camera was loaned to us by the Engineering and Physical Sciences Research Council Instrument Pool. The Kinexus Ultra Rheometer was purchased by the Engineering School with financial assistance from Advantage West Midlands and the European Regional Development Fund's Science City Research Alliance and we were assisted in the viscosity measurements (Fig.1) by Dr. Roger Thorpe of the Engineering School. We would also like to acknowledge the assistance of Mr. Dominic Hollingdale, who provided us with some of the background data for the parts that were measured in Section 3.3. 


\section{References}

Accordis, 1999. Safety Data Sheet, Al070, Issue B, AL070europeA, Accordis Fine Chemicals Ltd, Registered Office PO Box 5, Station Road, Spondon, Derby DE21 7BP.

Asnafi, N., 2001. On springback of double-curved autobody panels. International Journal of Mechanical Sciences 43, 5-37.

Ayres, R., 1983. The Limiting Dome Height (LDH) Test and The Grid Analyzer, In: Wagoner, R. (Ed.), Novel Techniques in Metal Deformation Testing. TMS, Warrendale, PA, p. 47.

Ayres, R., Brazier, W., Sajewski, V., 1979. Evaluating the GMR-Limiting Dome Height Test as a New Measure of Press Formability Near Plane Strain. J. Applied Metalworking 1, 41-49.

Barber, R., 1978. Non-Contact Temperature Measurement of Metal Surfaces in the Open. Advances in Instrumentation 33, 417-434.

Barnes, H., 2000. A Handbook of Elementary Rheology. The University of Wales Institute of Non-Newtonian Fluid Mechanics, Aberyswyth.

Blumel, K., G, H., P, L., 1988. Variations of the Stamping Process, Controlling Sheet Metal Forming Processes. ASM, Dearborn, USA, pp. 9-16.

Burger, G., Gupta, A., PW, J., DJ, L., 1995. Microstructural Control of Aluminium Sheet Used in Automotive Applications. Materials Characterization 35, 23-39.

Col, A., 2003. Investigation on Press Forming Scatter Origin, Proceedings of the 6th International ESAFORM COnference on Material Forming, pp. 183-186.

de Souza, T., Rolfe, B., 2008. Multivariate modelling of Variability in Sheet Metal Forming. Journal of Materials Processing Technology 203, 1-12.

Fischer, R., Schey, J., 1992. Tribological Factors Affecting the LDH Test, Proc. Of the SAE Intl Congress and Expo, pp. 57-61.

FLIR, 2003. FLIR ThermaCAM SC300 Manual: Thermographic Measurement Techniques, pp. 87-126.

Ghosh, A., 1975. The Effect of Lateral Drawing-In on Stretch Formability. Metals Engineering Quarterly, 75.

Go, J., WJ, P., Militzer, MA, W., 2003. Modelling Recovery and Recrystallisation durng annealing of AA5754 Aluminium Alloy. Materials Science and Technology 19, 1361-1368.

Graf, A., Izworski, N., 1993. Industrial Implementation of Practices for LDH Stability, Proc. Of the SAE Intl Congress and Expo, pp. 990-995.

Groche, P., Nitzsche, G., Elsen, A., 2008. Adhesive wear in Deep Drawing of Aluminium Sheets. CIRP Annals - Manufacturing Technology 57, 295-298. 
Haar, R.t., 1996. Friction in Sheet Metal Forming, The Influence of (Local) Contact Conditions and Deformation. University Twente.

Izworski, N., Graf, A., 1991. Obtaining LDH Stability, Proc. Of the SAE Intl Congress and Expo, pp. 41-45.

Li, D., Ghosh, A., 2003. Tensile Deformation Behaviour of Aluminium Alloys at Warm Temperatures. Materials Science and Engineering A352, 279-286.

Nelkon, M., Parker, P., 1982. Advanced Level Physics, 5th Edition ed. Hienemann Educational Books.

Newby, J., 1981. Temperature Changes Fromability of Sheet Metals, International Congress on Metal Engineering, Sheet Forming, Birmingham, UK, p. 14/11.

Pereira, M., Okonkwo, P., Yan, W., Rolfe, B., 2010. Deformation and Frictional Heating in Relation to Wear in Sheet Metal Stamping. Steel Research International 81, 713-716.

Polmear, I., 1995. Light Alloys, Metallurgy of the Light Metals. Arnold, a division of Hodder Headline plc.

Schey, J., 1983. Tribology in Metalworking. American Society for Metals.

Thompson, R., 1993. The LDH Test to Evaluate Sheet Metal Formability - Final Report of the LDH Committee of the North American Deep Drawing Research Group. SAE Technical Paper Series Paper No. 930815, 291-301.

Wang, C.-Y., Hancock, W., 1997. Minimizing Splits in the Automotive Stamping Process by Logistic Regression. Quality Engineering 9, 653-663.

Zhou, Z., Cao, X., 1994. Optimal Process Control in Stamping Operations. Quality Engineering 6, 621-631. 